Research Article

\title{
The Dynamic Rent-Seeking Games with Policymaker Cost and Competition Intensity
}

\author{
Yu Yu ${ }^{1,2}$ and Jia-Qian $X u^{1}$ \\ ${ }^{1}$ School of Economics, Zhejiang University of Finance \& Economics, Hangzhou, Zhejiang 310018, China \\ ${ }^{2}$ Center for Economic Behavior and Decision-Making, Zhejiang University of Finance \& Economics, Hangzhou, \\ Zhejiang 310018, China \\ Correspondence should be addressed to Yu Yu; yyuu_123@126.com
}

Received 26 April 2020; Accepted 4 August 2020; Published 25 September 2020

Academic Editor: Maria Alessandra Ragusa

Copyright (c) $2020 \mathrm{Yu} \mathrm{Yu} \mathrm{and} \mathrm{Jia-Qian} \mathrm{Xu.} \mathrm{This} \mathrm{is} \mathrm{an} \mathrm{open} \mathrm{access} \mathrm{article} \mathrm{distributed} \mathrm{under} \mathrm{the} \mathrm{Creative} \mathrm{Commons} \mathrm{Attribution}$ License, which permits unrestricted use, distribution, and reproduction in any medium, provided the original work is properly cited.

\begin{abstract}
In this paper, a dynamic rent-seeking game incorporating policymaker cost and competition intensity is considered. On the basis of the political environment and rent-seekers with incomplete information set, the locally asymptotic stability of Nash equilibrium is proved. The competition intensity and policymaker cost could enlarge the stability region of Nash equilibrium. The higher the competition intensity is, the more the opponent's expenditure reduces the player's success probability, which is beneficial to the maintenance of Nash equilibrium. The higher the policymaker cost is, the less easily both players succeed and the more stable the rent-seeking market is. As the competition parameter decreases or the expenditure parameter increases, there will be chaos in a rent-seeking market. Chaos control is in order to stabilize the equilibrium of the rent-seeking game.
\end{abstract}

\section{Introduction}

The rent-seeking phenomenon was observed by Tullock in welfare loss [1]. His research could be roughly divided into two directions: first, the welfare cost of rent-seeking behavior and, second, the economic analysis of rent-seeking political market. Krueger [2] first proposed that the government's restrictions produced the value of rent. The import permissions of India and Turkey were used to verify large losses caused by rent-seeking. Recently, rentseeking theory has developed rapidly. In early studies, most scholars considered the rent-seekers with risk neutrality. According to rent-seeking activity of expected return, they adjusted their own expenditure cost for rentseeking. This view was opposed by Buchanan et al. [3] in the rent-seeking game model. They systematically analyzed the social costs of rent-seeking. Their research focused on three issues. The first was the expenditure to obtain and maintain a monopoly for rent-seekers. The second was the expenditure to create rent for government officials. The last was the resource allocation distortions and social welfare losses caused by a monopoly which is produced by rent-seeking. In the lottery model of rentseeking, Tullock pointed out that rent-seekers' equilibrium expenditure may be more than, less than, and equal to the expected rent value return.

To make the game more accurate, costs for supplying rents were considered [4]. Increasing policymaker costs made lobbying less effective. In addition, scholars found that political competition among rent-seekers also influenced the rent-seeking outcome [5, 6]. Godwin et al. in [7] checked policymaker cost and competition intensity into the standard rent-seeking game. The lobbying process was discussed more specifically. They concluded that lobbying expenditures, rent-seeking profits, and rent dissipation depended on the intensity of competition and the value of the rent relative to policymaker costs. They considered comparative statics of expenditures and profits with respect to competition. Both Tullock's standard rentseeking model and Godwin's rent-seeking model of 
describing the political policy process could be summarized as static game models of complete information [7]. In the models, equilibrium was used to forecast the rentseeking behavior.

This kind of models requires players with complete information on game structure, complete rationality behavior, and best reaction capability. Under this strong assumption, players could reach Nash equilibrium through a strategy interaction. This result is based on the assumption that each firm knows the demand curve of the market and what his opponents decide to do, while, in reality, we often observe that the equilibrium is achieved through repeated interactions. Players may not be completely rational, and they have limited knowledge of demand function. Their profit maximization problem is solved by "rule of thumb" or market experiment. How to solve the rationality assumption in a game? If players are not completely rational, could the equilibrium be maintained? Traditional game theory combined with nonlinear dynamics attracts researchers' concerns.

To make the research more realistic, scholars put forward kinds of rationality expectations, which have formed the cornerstone of this field, such as bounded rationality, adaptive expectation, naïve rationality, and local monopolistic approach (LMA). This kind of research could be applied to motive the competition and changes in the biological systems over time. Costa et al. [8] verified the existence of numerous similarities between the samples of the Leiden herbarium which emphasize the importance and the usefulness of the herbarium in question for the processes of typification. Ferrauto et al. [9] charted and assessed the state of fragmentation and disturbance of areas of apiarian interest, caused by the presence of urban infrastructure and road networks. The supply chain quality management and decisions were considered in competition $[10,11]$.

Most literature applies this method in the production market; there is almost no article referring to a rent-seeking market. Homogeneous products first attracted much concern. Cournot and Bertrand model was modified and improved by researchers. Nonlinear demand and cost functions increased the complexity of dynamic game [12-15]. Ahmed and Elettreby in [16] introduced a multimarket Cournot model using Puu's approach [17]. Bischi et al. [18] considered a model with a fixed fraction of firms in two complementary groups: Best Reply and LMA adjustment. The Cournot-Bertrand mixed duopoly game offered a new research possibility. Two firms competing with price and output, respectively, came to some different conclusions [19-21]. Besides the static model of Cournot and Bertrand, the Stackelberg model describes two players with sequential actions. Researchers analyzed chaotic dynamic behaviors in the models [22-24].

The effect of differentiated goods on chaos is also an interesting topic in this field [25-27]. Researchers reached a consensus on the result that bounded rationality with delay enlarged stability region [28-31]. Chaos control also became an important issue that most scholars focused on [16, 32, 33].
In the literature mentioned above, chaos theory is mainly applied in the production of duopoly market. Different demand and cost functions are discussed sufficiently. Firms' maximization profit problem and classical game model are familiar to researchers. Our study aims at analyzing a dynamic rent-seeking game with policymaker cost and competition intensity. Not only the adjustment parameter of expenditure but also the competition intensity could affect the stability of the rent-seeking market. In our paper, we first point out the deficiency of the model in [7]. Their study could not exclude the possibility of multiequilibrium. We demonstrate that the Nash equilibrium of the rent-seeking game is unique and symmetrical. In addition, rentseekers' success probability is not common knowledge of each other. They adjust their expenditure functions according to a gradient rule. Chaos phenomenon is observed in a rent-seeking market.

The paper is arranged as follows. In Section 2, the uniqueness and symmetry of Nash equilibrium are proved. In Section 3, a dynamic rent-seeking game model with policymaker cost and competition intensity is constructed. We discuss the locally asymptotic stability of the Nash equilibrium. In Section 4, some simulation results are presented. In Section 5, we draw some conclusions through theoretical analysis and numerical simulation.

\section{A Rent-Seeking Game with Policy Cost and Competition Intensity}

Godwin et al. improved Tullock's lottery model of rentseeking [7]. They checked a policymaker cost $N$ for supplying a rent value $V(>N)$ and a rent-seeking competition intensity $\alpha \in(0,1]$ into Tullock's standard rent-seeking model. The greater $\alpha$ is, the more intense the competition of rent-seeking is. It is assumed that the player $i$ 's rent expenditure is $R_{i}(i=1,2)$. The player $i$ 's success probability function for rent-seeking has been formulated: $P_{i}=R_{i} /$ $\left(R_{i}+\alpha R_{j}+N\right),(i, j=1,2, i \neq j)$, which means player $i$ may fail in this rent-seeking process. In the static game with complete information and complete rationality of players, player $i$ chooses $R_{i} \geq 0$ for the fixed $R_{j}$. To solve the maximization problem:

$$
\max \pi_{i}\left(R_{i}, R_{j}\right)=\frac{R_{i} V}{\left(R_{i}+\alpha R_{j}+N\right)}-R_{i}
$$

The optimal first-order condition of formula (1) is

$$
\frac{\partial \pi_{i}}{\partial R_{i}}=\frac{\left(\alpha R_{j}+N\right) V}{\left(R_{i}+\alpha R_{j}+N\right)^{2}}-1=0
$$

Checking formula (2), it is clear that the best response functions $N_{1}\left(R_{2}\right), N_{2}\left(R_{1}\right)$ of both players are 


$$
N_{1}\left(R_{2}\right)= \begin{cases}\sqrt{\left(\alpha R_{2}+N\right) V}-\alpha R_{2}-N, & 0 \leq R_{2} \leq \frac{(V-N)}{\alpha}, \\ 0, & R_{2}>\frac{(V-N)}{\alpha},\end{cases}
$$

$$
N_{2}\left(R_{1}\right)= \begin{cases}\sqrt{\left(\alpha R_{1}+N\right) V}-\alpha R_{1}-N, & 0 \leq R_{1} \leq \frac{(V-N)}{\alpha}, \\ 0, & R_{1}>\frac{(V-N)}{\alpha} .\end{cases}
$$

The intersection point of the two response function curves is Nash equilibrium $\left(R_{1}^{e}, R_{2}^{e}\right)$ of the game. In [7], the model could not exclude the possibility of multiequilibrium. We will prove that the Nash equilibrium is unique and symmetrical. Firstly, we need two lemmas as follows.

Lemma 1. The Nash equilibrium of complete information static rent-seeking game with policymaker cost and competition intensity exists.

You may refer to Godwin's proof process in [7].

Lemma 2. The Nash equilibrium $\left(R_{1}^{e}, R_{2}^{e}\right)$ satisfies $R_{i}^{e} \in[0,(V-N) / \alpha], 1=1,2$.

Proof. We use reduction to absurdity. It is assumed that $R_{1}^{e}>(V-N) / \alpha$.

Check formula (4); we know $R_{2}^{e}=0$.

When $\quad R_{2}^{e}=0, \quad R_{1}^{e}=\sqrt{\left(\alpha R_{2}^{e}+N\right) V}-\alpha R_{2}^{e}-N=\sqrt{V N}-$ $N<(V-N) / \alpha$ from formula (3). There is a contradiction. Therefore, $R_{1}^{e} \in[0,(V-N) / \alpha]$. Similarly, $R_{2}^{e} \in[0,(V-N) / \alpha]$ QED.

From the two lemmas above, we could prove that the static game of complete information has only one symmetric Nash equilibrium.

Theorem 1. If $\left(R_{1}, R_{2}\right)$ is the Nash equilibrium of the game model, $R_{1}=R_{2}=R_{e}$ must be satisfied, where $R_{e}=\alpha V-2 N(1+\alpha)+\sqrt{\alpha^{2} V^{2}+4(1+\alpha) N V} / 2(1+\alpha)^{2}$.

Proof. We assume that $\left(R_{1}, R_{2}\right)$ is the Nash equilibrium; if $R_{1} \neq R_{2}$ from Lemma 2, we know, $R_{i} \in[0,(V-N) / \alpha]$, $i=1,2$. Checking formulas (3) and (4), we know

$$
R_{1}+\alpha R_{2}-\sqrt{\left(\alpha R_{2}+N\right) V}=R_{2}+\alpha R_{1}-\sqrt{\left(\alpha R_{1}+N\right) V},
$$

that is,

$$
(1-\alpha)\left(R_{1}-R_{2}\right)+\sqrt{\left(\alpha R_{1}+N\right) V}=\sqrt{\left(\alpha R_{2}+N\right) V} .
$$

Square the ends of the above equation:

$$
\begin{aligned}
& (1-\alpha)^{2}\left(R_{1}-R_{2}\right)^{2}+2(1-\alpha)\left(R_{1}-R_{2}\right) \sqrt{\left(\alpha R_{1}+N\right) V} \\
& +\left(\alpha R_{1}+N\right) V=\left(\alpha R_{2}+N\right) V,
\end{aligned}
$$

that is,

$$
\begin{aligned}
& (1-\alpha)^{2}\left(R_{1}-R_{2}\right)^{2}+2(1-\alpha)\left(R_{1}-R_{2}\right) \sqrt{\left(\alpha R_{1}+N\right) V} \\
& +\alpha V\left(R_{1}-R_{2}\right)=0 .
\end{aligned}
$$

Both ends of the equation are divided by $R_{1}-R_{2}(\neq 0)$ :

$$
(1-\alpha)^{2}\left(R_{1}-R_{2}\right)+2(1-\alpha) \sqrt{\left(\alpha R_{1}+N\right) V}+\alpha V=0 .
$$

Checking formula (4), $\sqrt{\left(\alpha R_{1}+N\right) V}=R_{2}+\alpha R_{1}+N$, we have the following equation:

$$
(1-\alpha)(1+\alpha)\left(R_{1}+R_{2}\right)+2 N(1-\alpha)+\alpha V=0 .
$$

But the left end is positive and there is a contradiction. So, $R_{1}=R_{2}$

We prove that the Nash equilibrium $\left(R_{1}, R_{2}\right)$ which satisfies $R_{1}=R_{2}$ is unique. In formula (3) or (4), let $R_{1}=R_{2}=R_{e}$; we get the quadratic equation about $R_{e}$ :

$$
(1+\alpha)^{2} R_{e}^{2}+(2 N(1+\alpha)-\alpha V) R_{e}+N(N-V)=0 .
$$

The solution of the equation is

$$
\frac{\left(\alpha V-2 N(1+\alpha) \pm \sqrt{\alpha^{2} V^{2}+4(1+\alpha) N V}\right)}{2(1+\alpha)^{2}} .
$$

Because the expenditure for rent-seeking is nonnegative, the minus in front of the radical sign of the molecule in the above equation is removed. We get the rent-seekers' equilibrium expenditure:

$$
R_{e}=\frac{\left(\alpha V-2 N(1+\alpha)+\sqrt{\alpha^{2} V^{2}+4(1+\alpha) N V}\right)}{2(1+\alpha)^{2}} \cdot \text { QED. }
$$

In [7], it has given comparative static results on the basis of the Nash equilibrium $\left(R_{e}, R_{e}\right)$. However, the rent seekers' complete information and rationality are not always satisfied. Therefore, a dynamic rent-seeking game problem with limited rationality needs to be considered.

\section{A Dynamic Rent-Seeking Game with Gradient Rule Based on Marginal Profit}

In this section, we assume that the rent-seekers have no complete information of success probability function and rent value and players have no expectation capability of complete rationality. According to Dixit's assumption of bounded rationality behavior [34], we only assume that player $i$ adjusts his own expenditure for rent-seeking $R_{\iota}^{\prime}$ next 
period according to expenditure for rent-seeking $R_{i}$ and marginal profit $\partial \pi_{i} / \partial R_{i}=\left(\left(\alpha R_{j}+N\right) V /\left(R_{i}+\alpha R_{j}+N\right)^{2}\right)-$ 1 in the current period. Thus, the rent seeker's expenditure growth rate is proportional to his marginal profit, that is,
$\left(R_{i}^{\prime}-R_{i}\right) / R_{i}=u_{i}\left(\partial \pi_{i} / \partial R_{i}\right), i=1,2$, where $u_{i}>0$ is the rentseeker's adjustment parameter of expenditure. Thus, we construct a dynamic system of the rent-seeking game:
The limit state of the system depends on its fixed points. Thus, we solve the algebraic equations as follows:

$$
\left\{\begin{array}{l}
u_{1} R_{1}\left(\frac{\left(\alpha R_{2}+N\right) V}{\left(R_{1}+\alpha R_{2}+N\right)^{2}}-1\right)=0 \\
u_{2} R_{2}\left(\frac{\left(\alpha R_{1}+N\right) V}{\left(R_{2}+\alpha R_{1}+N\right)^{2}}-1\right)=0
\end{array}\right.
$$

The solutions of the equations are the four fixed points:

$$
\begin{aligned}
& E_{0}=(0,0), \\
& E_{1}=(0, \sqrt{N V}-N), \\
& E_{2}=(\sqrt{N V}-N, 0), \\
& E_{*}=\left(R_{e}, R_{e}\right) .
\end{aligned}
$$

$E_{0}, E_{1}, E_{2}$ are the boundary equilibria and $E_{*}$ is the Nash equilibrium. $R_{e}$ is given in Theorem 1 .

To forecast the limit state of a dynamic game, the stability of the fixed points should be considered. Thus, we consider the Jacobian matrix of system (14):

$$
J=\left[\begin{array}{cc}
1+u_{1}\left(\frac{\left(\alpha R_{2}+N\right)\left(\alpha R_{2}-R_{1}+N\right) V}{\left(R_{1}+\alpha R_{2}+N\right)^{3}}-1\right) & \frac{\alpha u_{1} R_{1}\left(R_{1}-\alpha R_{2}-N\right) V}{\left(R_{1}+\alpha R_{2}+N\right)^{3}} \\
\frac{\alpha u_{2} R_{2}\left(R_{2}-\alpha R_{1}-N\right) V}{\left(R_{2}+\alpha R_{1}+N\right)^{3}} & 1+u_{2} \frac{\left(\alpha R_{1}+N\right)\left(\alpha R_{1}-R_{2}+N\right) V}{\left(R_{2}+\alpha R_{1}+N\right)^{3}}-1
\end{array}\right] .
$$

At $E_{0}$, the Jacobian matrix is

$$
J\left(E_{0}\right)=\left[\begin{array}{cc}
1+u_{1}\left(\frac{V}{N}-1\right) & 0 \\
0 & 1+u_{2}\left(\frac{V}{N}-1\right)
\end{array}\right] .
$$

Because $V>N$, the characteristic roots of are $J\left(E_{0}\right) \lambda_{1}=1+u_{1} \quad(V / N-1)>1, \quad \lambda_{2}=1+u_{2} \quad(V / N-1)>1$. Thus, $E_{0}$ is unstable.

At $E_{1}$, the Jacobian matrix is

$$
J\left(E_{1}\right)=\left[\begin{array}{cc}
1+u_{1}\left(\frac{V-N-\alpha(\sqrt{N V}-N)}{\alpha \sqrt{N V}+(1-\alpha) N}\right) & 0 \\
\alpha u_{2}(\sqrt{N V}-N) \frac{\sqrt{N V}-2 N}{(N V)^{3 / 2}} & 1+u_{2}\left(\frac{N V(2 N-\sqrt{N V})}{(N V)^{3 / 2}}-1\right)
\end{array}\right] .
$$

One of the characteristic roots of $J\left(E_{1}\right)$ : is $\lambda_{1}=1+u_{1}((V-N-\alpha(\sqrt{N V}-N)) /(\alpha \sqrt{N V}+(1-\alpha) N))$

$>1$. Thus, the fixed point $E_{1}$ is unstable.
At $E_{2}$, the Jacobian matrix is 


$$
J\left(E_{2}\right)=\left[\begin{array}{cc}
1+u_{1}\left(\frac{N V(2 N-\sqrt{N V})}{(N V)^{3 / 2}}-1\right) & \alpha u_{1}(\sqrt{N V}-N) \frac{\sqrt{N V}-2 N}{(N V)^{3 / 2}} \\
0 & 1+u_{2}\left(\frac{V-N-\alpha(\sqrt{N V}-N)}{\alpha \sqrt{N V}+(1-\alpha) N}\right)
\end{array}\right] .
$$

One of the characteristic roots of $J\left(E_{2}\right)$ is $\lambda_{2}=$ $1+u_{2}((V-N-\alpha(\sqrt{N V}-N)) /(\alpha \sqrt{N V}+(1-\alpha) N))>1$. Thus, the fixed point $E_{2}$ is also unstable.

Finally, at $E_{*}$, the Jacobian matrix of the Nash equilibrium is

$$
J\left(E_{*}\right)=\left[\begin{array}{cc}
1-\frac{2 R(\alpha R+N) V}{A} u_{1} & \alpha V R \frac{(1-\alpha) R-N}{A} u_{1} \\
\alpha V R \frac{(1-\alpha) R-N}{A} u_{2} & 1-\frac{2 R(\alpha R+N) V}{A} u_{2}
\end{array}\right],
$$

where $R=R_{e}, A=((1+\alpha) R+N)^{3}$.

The characteristic polynomial of $J\left(E_{*}\right)$ is $f(\lambda)=$ $\lambda^{2}-T \lambda+D$, where $T$ is the trace of $J\left(E_{*}\right), T=2-$ $(2 R(\alpha R+N) V / A)\left(u_{1}+u_{2}\right) D$ is the determinant of $J\left(E_{*}\right)$,
$D=\left(1-(2 R(\alpha R+N) V / A) u_{1}\right)\left(1-(2 R(\alpha R+N) V / A) u_{2}\right)-$ $(\alpha V R((1-\alpha) R-N / A))^{2} u_{1} u_{2}$.

Because the discriminant is $\Delta=T^{2}-4 D=((2 R V$ $\left.(\alpha R+N) / A) u_{1}-(2 R V(\alpha R+N) / A) u_{2}\right)^{2}+4(\alpha V R(1-\alpha) R-$ $N / A)^{2}>0$, the characteristic roots of $J\left(E_{*}\right)$ are real values. $|\lambda|<1$ if and only if Jury conditions are established as follows:

$$
\left\{\begin{array}{l}
(1) 1+D-T>0, \\
(2) 1+D+T>0, \\
(3) D<1 .
\end{array}\right.
$$

Firstly, $\quad 1+D-T=\left[(2 R V(\alpha R+N) / A)^{2}-(\alpha R V((1-\alpha)\right.$ $\left.u-N) / A)^{2}\right] u_{1} u_{2}>0$; thus, the stability of $E_{*}$ depends on formulas (2) and (3) in Jury's conditions.

That is,

$$
\begin{gathered}
D<1 \Longleftrightarrow\left(\frac{1}{2 A}\left((2 R V(\alpha R+N))^{2}-(\alpha R V((1-\alpha) R-N))^{2} u_{1}-R V(\alpha R+N)\right)\right) u_{2}<R V(\alpha R+N) u_{1}, \\
1+D+T>0 \Longleftrightarrow\left(\frac{1}{4 A}\left((2 R V(\alpha R+N))^{2}-\left(\alpha R V((1-\alpha) R-N)^{2}\right)\right) u_{1}-R V(\alpha R+N)\right) u_{2}>R V(\alpha R+N) u_{1}-A .
\end{gathered}
$$

In summary, we get the following conclusion.

Theorem 2. The boundary equilibriums $E_{0}, E_{1}$, and $E_{2}$ are unstable. The Nash equilibrium $E_{*}$ is locally asymptotically stable if parameters $V, N, \alpha, u_{1}, u_{2}$ satisfy

$$
\left\{\begin{array}{l}
{\left[\frac{1}{4 A}\left((2 R V(\alpha R+N))^{2}-\left(\alpha R V((1-\alpha) R-N)^{2}\right) u_{1}-R V(\alpha R+N)\right)\right] u_{2}>R V(\alpha R+N) u_{1}-A} \\
{\left[\frac{1}{2 A}\left((2 R V(\alpha R+N))^{2}-(\alpha R V((1-\alpha) R-N))^{2} u_{1}-R V(\alpha R+N)\right)\right] u_{2}<R V(\alpha R+N) u_{1}} \\
u_{1} \geq 0, u_{2} \geq 0
\end{array}\right.
$$

Checking Theorem 2, we know the stability region $S$ of $E_{*}$ about adjustment parameters of expenditure for rent-seeking $u_{1}$ and $u_{2}$ is surrounded by $u_{2}\left(u_{1}\right)=\left(\left(R V(\alpha R+N) u_{1}-A\right) /\right.$ $(1 / 4 A)\left((2 R V(\alpha R+N))^{2}-(\alpha R V((1-\alpha) R-N))^{2}\right) \quad u_{1}-$ $R V(\alpha R+N)), u_{1} \geq 0$, and $u_{2} \geq 0$. The intersections of $u_{2}=u_{2}\left(u_{1}\right)$ and $u_{1}, u_{2}$ axis are $(A / R V(\alpha R+N), 0)$ and $(0, A / R V(\alpha R+N))$. The stability region $S$ is as Figure 1 shows.
When the parameters $u_{1}, u_{2}$ are in the stability region $S$, in the dynamic rent-seeking game, players adjust the expenditure for rent-seeking based on a gradient rule and achieve the Nash equilibrium of complete information static rent-seeking game with complete rationality ultimately. The Nash equilibrium could be used to analyze and forecast the result of the rent-seeking game. However, when the expenditure parameters for rent-seeking are not in the stability 
region $S$, we need to use a numerical simulation method to discuss the complexity of the limit state of the dynamic rentseeking game with incomplete rationality.

\section{Numerical Simulation}

In this section, complicated behaviors of the dynamic rentseeking game model are presented by simulation. A series of bifurcation and chaos with respect to $u_{2}$ and $\alpha$, the largest Lyapunov exponent, the strange attractors, and the sensitivity on initial values are shown in the figures. The sensitivity dependence on initial value is investigated. We set the parameters as follows: $V=10, N=5, \alpha=0.5$, and $u_{1}=4.1$, so $R^{*}=1.78, A / R V(\alpha R+N)=4.304$. Then, draw a bifurcation diagram with respect to $u_{2}$ (the adjustment speed of firm 2) when $u_{1}=4.1$ as Figure 2 shows. It is easy to see when $u_{2} \in(0,2.6510)$ that the system is in the Nash equilibrium state. When $u_{2}$ exceeds 2.6510 , a bifurcation behavior occurs. Period-doubling bifurcation and chaos begin to appear when $u_{2}>2.6510$. A large value of expenditure parameters converges to a more complicated economic behavior.

Figure 3 is the largest Lyapunov exponent with respect to $u_{2}$. A positive value means a chaotic phenomenon. It is evident that $L_{1}, L_{2}, L_{3}$, and $L_{4}$ in Figure 3 correspond to the first, second, third, and fourth bifurcation point in Figure 2, respectively. When $u_{2} \in(0,2.6510)$, the dynamic system is in the Nash equilibrium state. The first bifurcation occurs when $u_{2} \in(2.6510,4.2370)$; the second bifurcation occurs when $u_{2} \in(4.2370,4.5580)$; the third bifurcation occurs when $u_{2} \in(4.5580,4.6060)$; and chaos occurs when $u_{2} \in(4.6060,4.6190)$. After $u_{2}=4.6190$, the largest Lyapunov exponents are always positive.

The strange attractor is plotted in Figure 4.

Keeping other parameters fixed $(V=10, N=5)$, Figure 5 presents the effect of different $\alpha$ on the stability of the system. Keeping other parameters fixed $(V=10, \alpha=0.5)$, Figure 6 presents the effect of different $N$ on the stability of the system. The expression of stability region $S$ indicated that the increase of competition intensity or policymaker cost for supplying a rent heightens the stability of the rent-seeking market. The competition intensity $\alpha$ signifies the importance to player $i$ of player $j$ 's lobbying expenditures. The higher $\alpha$ is, the more player $j$ 's expenditure reduces player $i$ 's success probability, which is beneficial to the maintenance of Nash equilibrium. For any $N>0, P_{i}, P_{j}<1$. Therefore, it is possible that neither rent seeker wins the rent. The higher $N$ is, the less easily both players succeed and the more stable the rentseeking market is. It means that even though the players adjust the expenditure parameter faster, the rent-seeking market is still relatively stable with a bigger $N$.

Figure 7 is the bifurcation diagram with respect to $\alpha$. As the competition parameter increases, chaos would be weakened in a rent-seeking market.

The sensitivity on the initial values has been demonstrated as follows. Considering different $u_{2}$, subgraph 1 and subgraph 2 represent the orbits of $R_{1}$ with different initial values $\left(R_{10}, R_{20}\right)=(2,1.9)$ and $\left(R_{10}, R_{20}\right)=(2.001,1.9)$ from Figures $8-10$. In the three figures, $u_{2}=2, u_{2}=4$, and $u_{2}=4.8$ represent equilibrium, bifurcation, and chaos in the state of

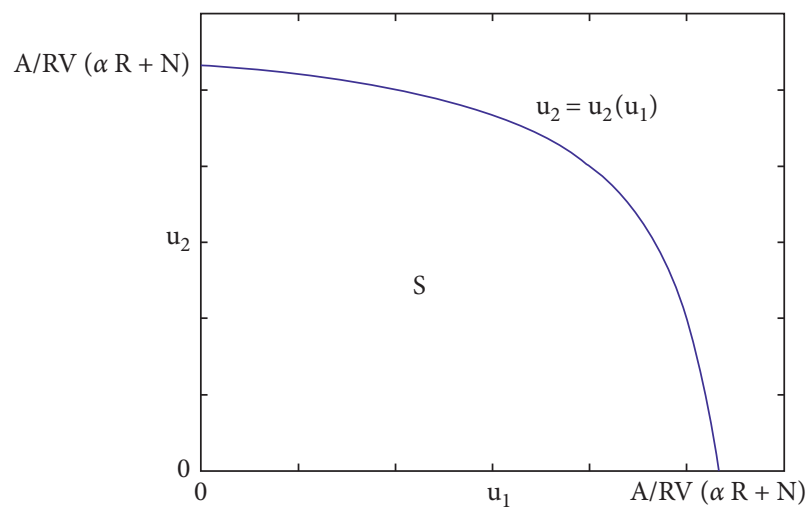

FIgURE 1: The stability region of $E_{*}$ with respect to adjustment parameters of expenditure $u_{1}, u_{2}$.

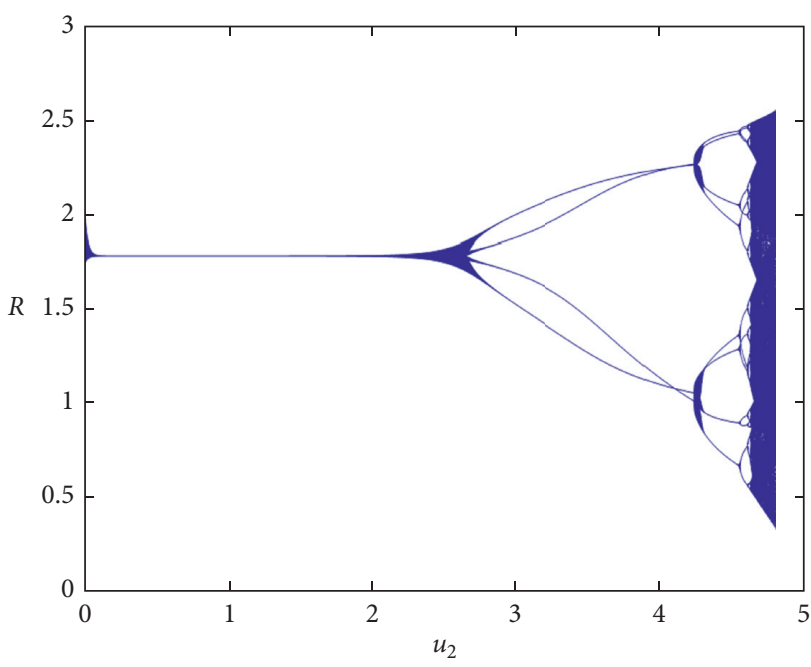

FIGURE 2: Bifurcation diagram with respect to $u_{2}$.

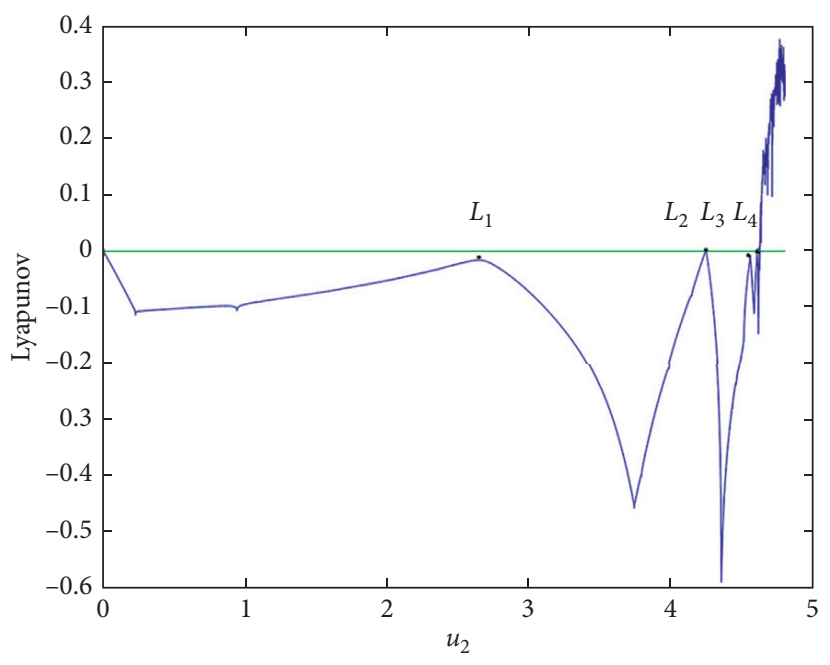

FIGURE 3: Lyapunov exponent diagram with respect to $u_{2}$.

system, respectively. As $t$ increases, a tiny change $\Delta=0.001$ of $R_{1}$ could cause a dramatic fluctuation only when the system is in chaos $\left(u_{2}=4.8\right)$ in Figure 10. 


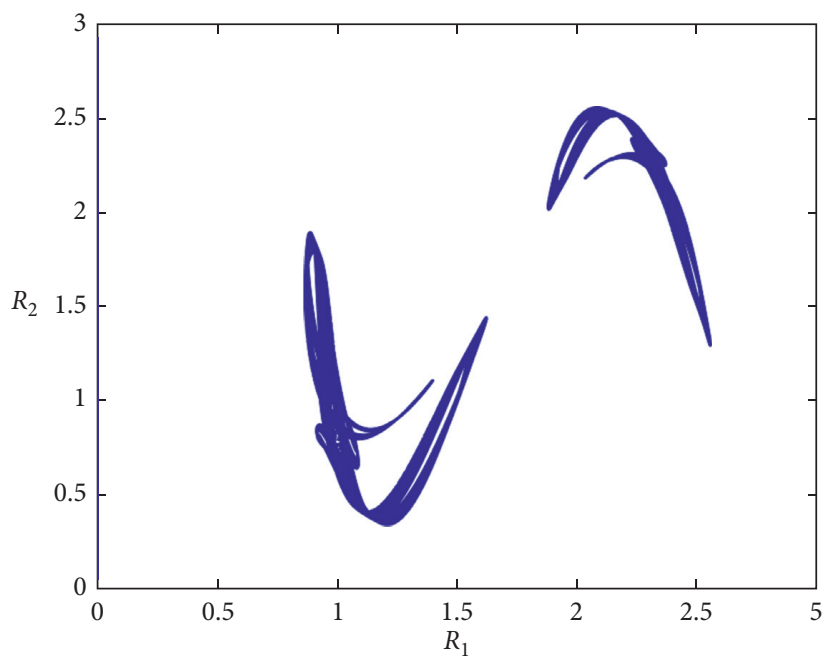

FIGURE 4: Strange attractor for $u_{1}=4.1$ and $u_{2}=4.8$.

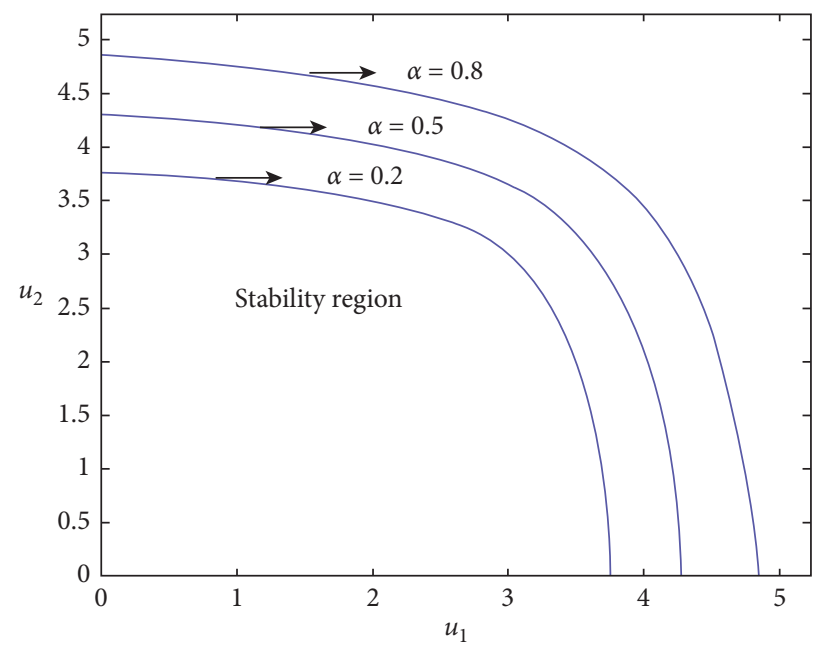

FIgURE 5: Stability region with a variable $\alpha$.

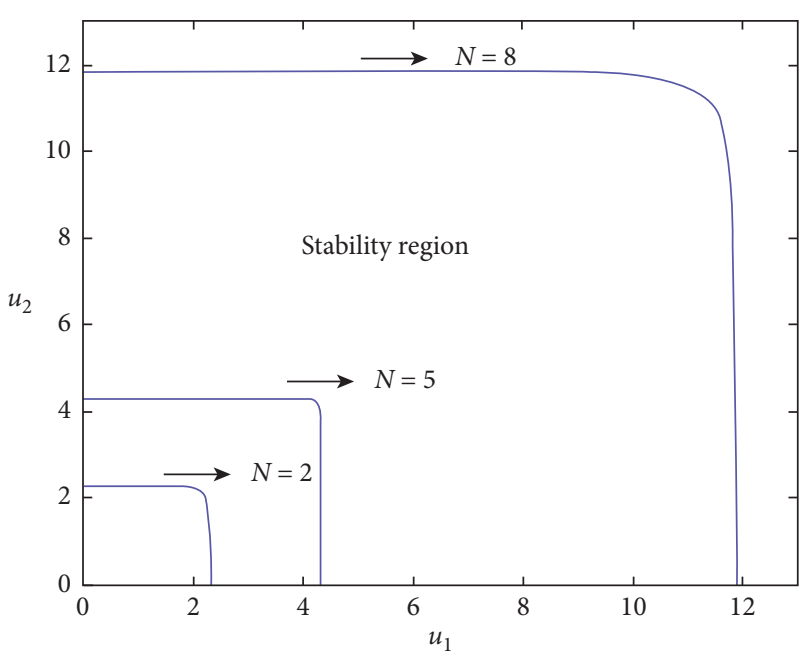

FIGURE 6: Stability region with a variable $N$.
Subgraph 1 and subgraph 2 represent the orbits of $R_{2}$ with different initial values $\left(R_{10}, R_{20}\right)=(2,1.9)$ and $\left(R_{10}, R_{20}\right)=(2$, 1.901) from Figures 11-13. In the three figures, $u_{2}=2, u_{2}=4$, and $u_{2}=4.8$ represent equilibrium, bifurcation, and chaos in the state of the system, respectively. As $t$ increases, a tiny change $\Delta=0.001$ of $R_{2}$ could cause a dramatic fluctuation only when the system is in chaos $\left(u_{2}=4.8\right)$ in Figure 13.

Figure 14 shows the map of bifurcation with respect to control factor $k$. The feedback control method is used to delay and eliminate chaos. The expenditure for rent-seeking finally stabilizes at the equilibrium levels $\left(R_{1}^{*}=R_{2}^{*}=1.7839\right)$ as Figure 15 shows. Figure 16 presents the effects of control factor $k$ on profits. The rent-seekers' profits finally stabilize at the equilibrium levels $\left(\pi_{1}^{*}=\pi_{2}^{*}=0.5401\right)$.

\section{Conclusions}

Godwin et al. [7] used a comparative static method to analyze an improved rent-seeking model. They checked the 


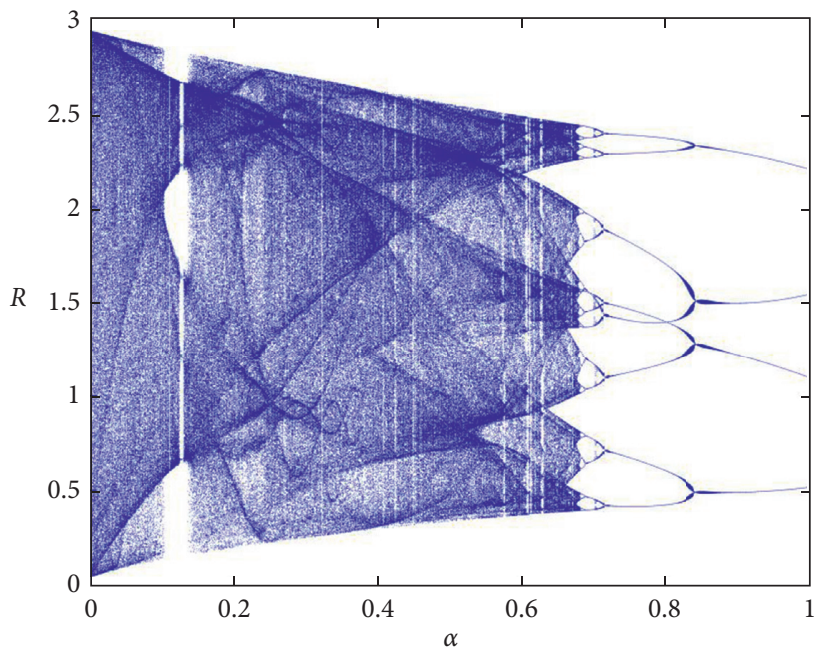

Figure 7: Bifurcation diagram with respect to $\alpha$.

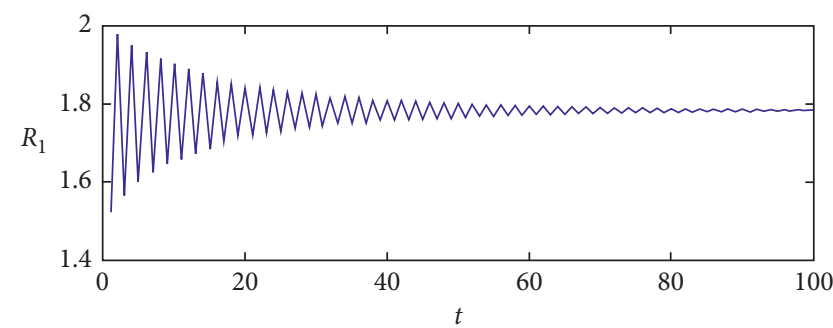

(a)

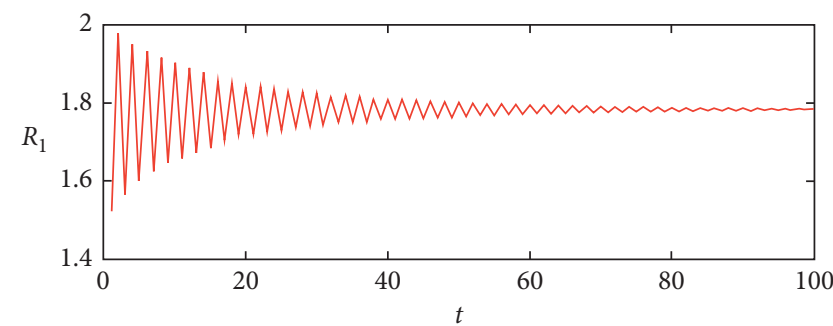

(b)

FIGURE 8: Orbits of $R_{1}$ with $\left(R_{10}, R_{20}\right)=(2,1.9)$ and $\left(R_{10}, R_{20}\right)=(2.001,1.9)$ of initial values $\left(u_{2}=2\right)$.

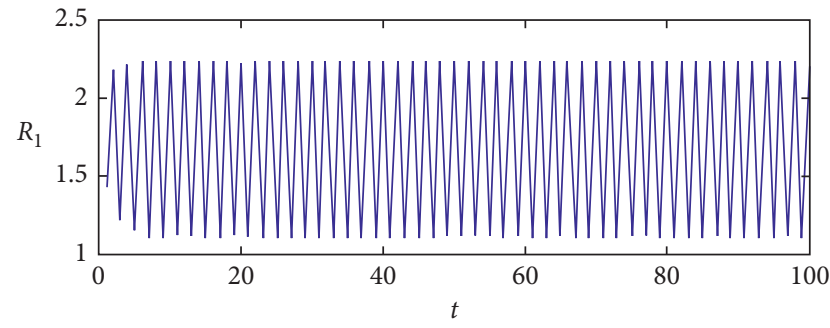

(a)

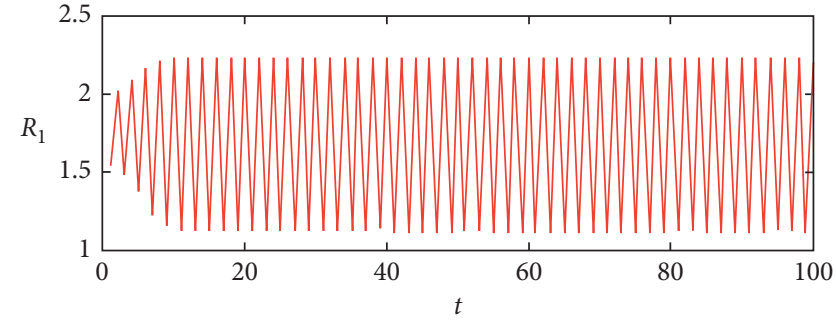

(b)

Figure 9: Orbits of $R_{1}$ with $\left(R_{10}, R_{20}\right)=(2,1.9)$ and $\left(R_{10}, R_{20}\right)=(2.001,1.9)$ of initial values $\left(u_{2}=4\right)$.

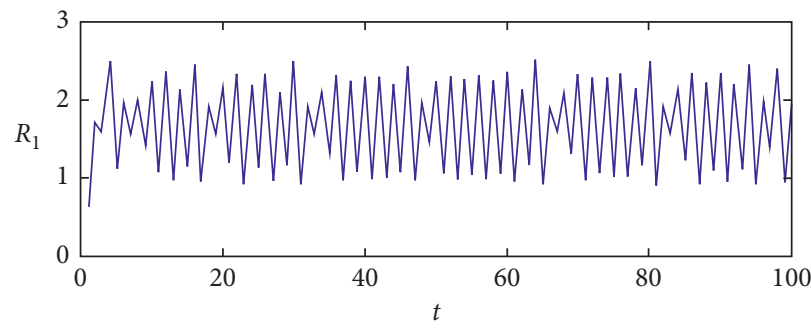

(a)

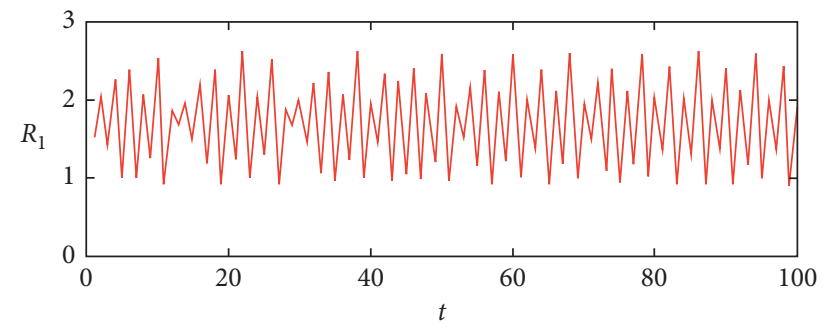

(b)

FIgURE 10: Orbits of $R_{1}$ with $\left(R_{10}, R_{20}\right)=(2,1.9)$ and $\left(R_{10}, R_{20}\right)=(2.001,1.9)$ of initial values $\left(u_{2}=4.8\right)$. 


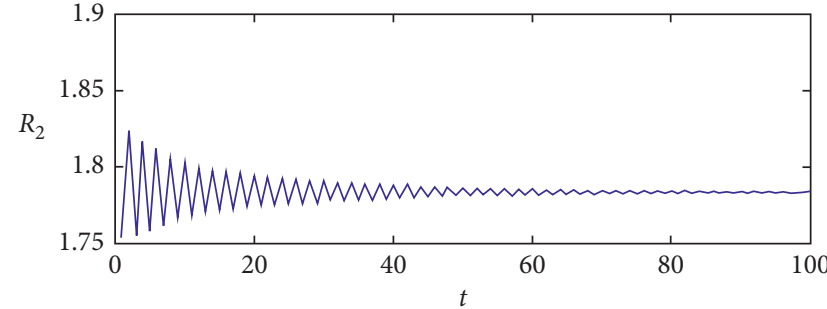

(a)

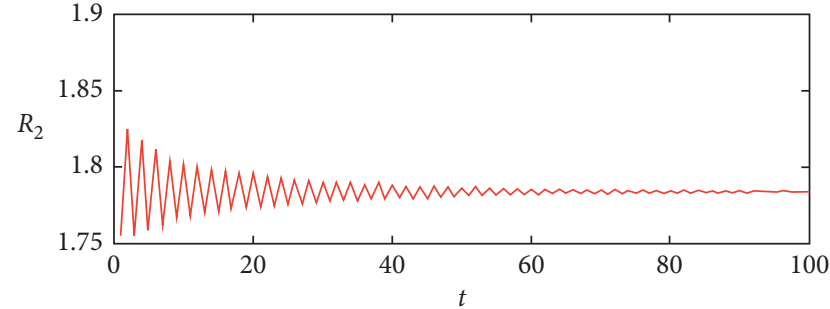

(b)

FIgURE 11: Orbits of $R_{2}$ with $\left(R_{10}, R_{20}\right)=(2,1.9)$ and $\left(R_{10}, R_{20}\right)=(2,1.901)$ of initial values $\left(u_{2}=2\right)$.

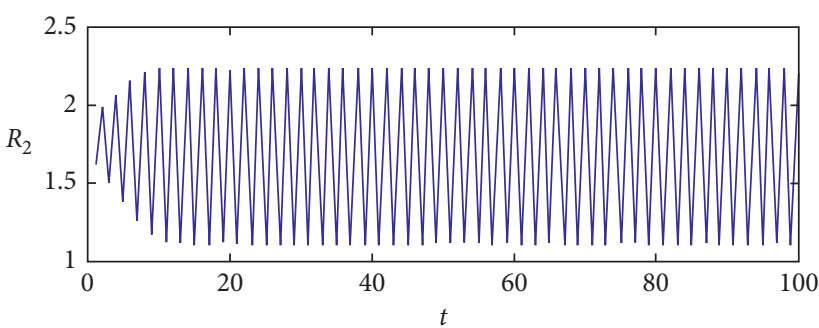

(a)

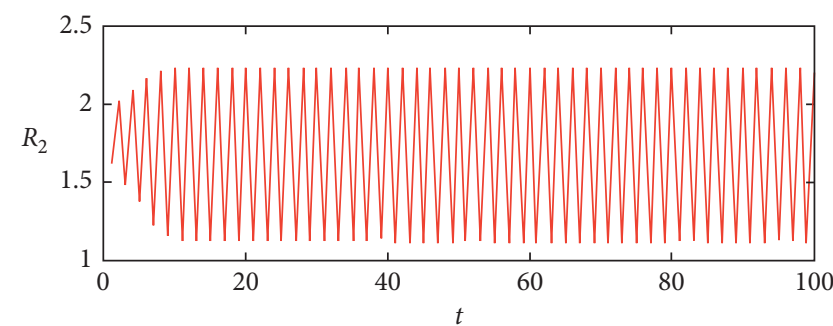

(b)

Figure 12: Orbits of $R_{2}$ with $\left(R_{10}, R_{20}\right)=(2,1.9)$ and $\left(R_{10}, R_{20}\right)=(2,1.901)$ of initial values $\left(u_{2}=4\right)$.

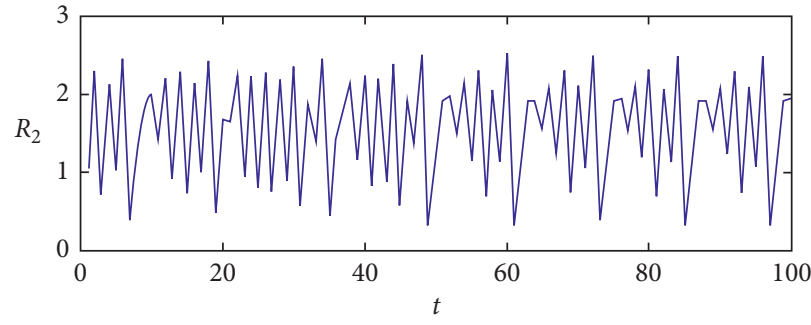

(a)

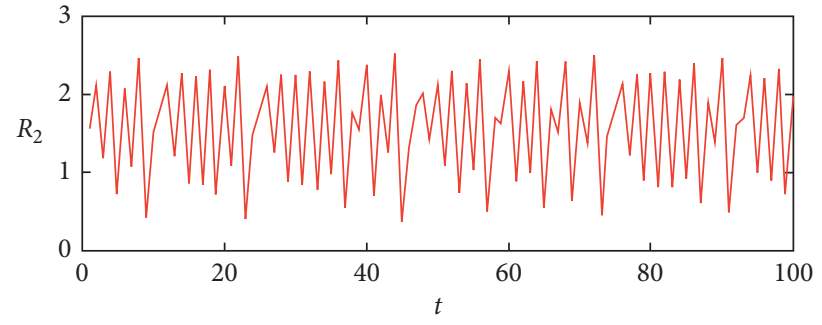

(b)

FIGURE 13: Orbits of $R_{2}$ with $\left(R_{10}, R_{20}\right)=(2,1.9)$ and $\left(R_{10}, R_{20}\right)=(2,1.901)$ of initial values $\left(u_{2}=4.8\right)$.

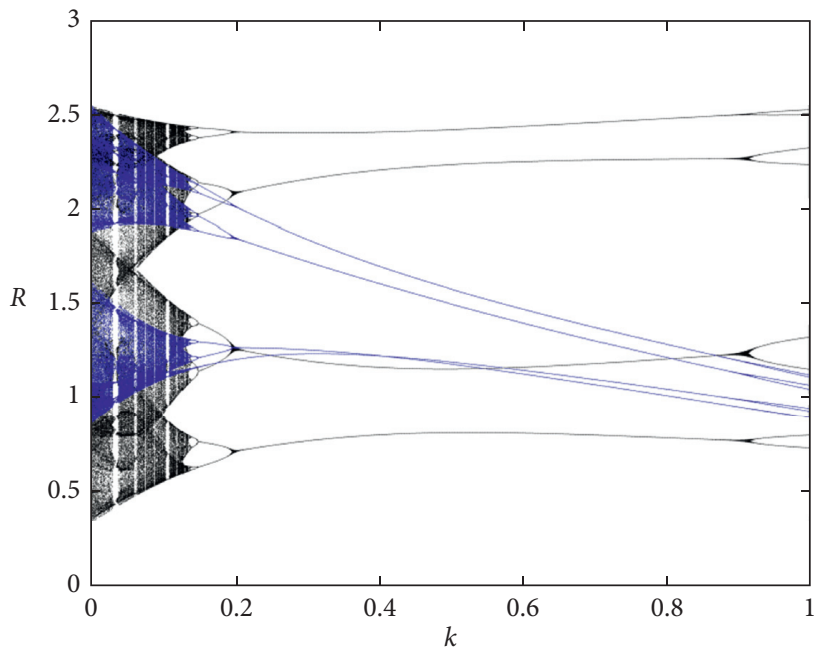

Figure 14: Bifurcation diagram with respect to control factor $k$. 


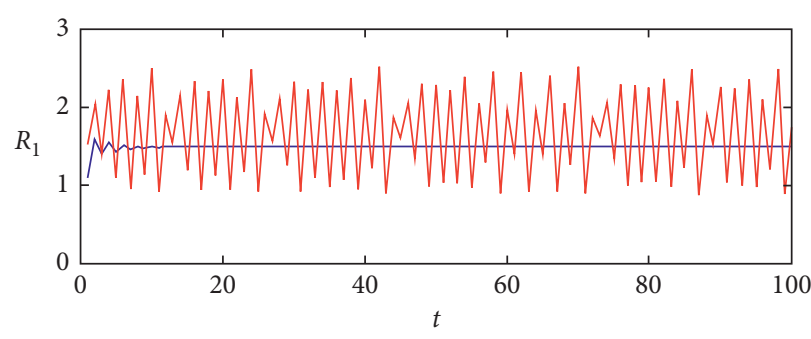

(a)

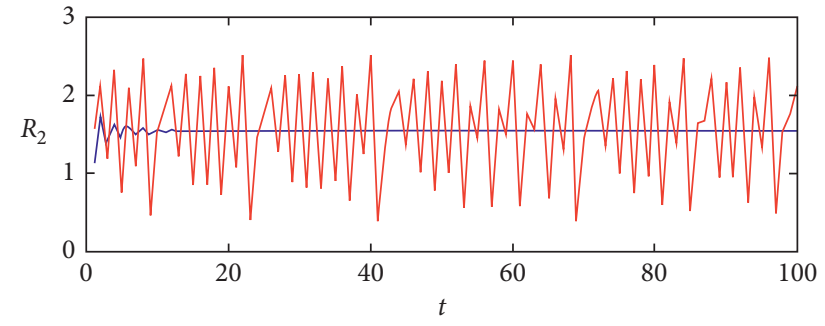

(b)

FIGURE 15: Effects of control factor $k$ on $R_{1}, R_{2}(k=0.4)$.

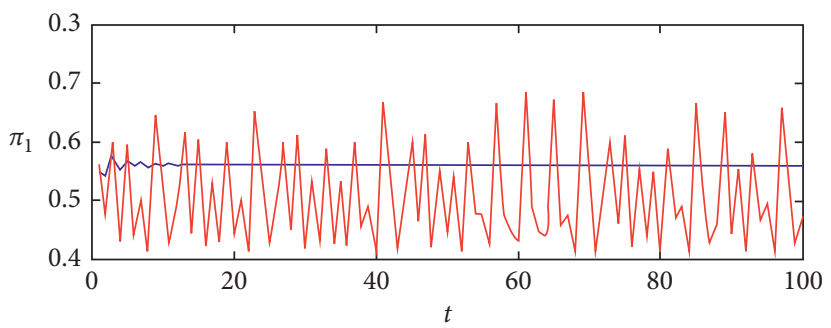

(a)

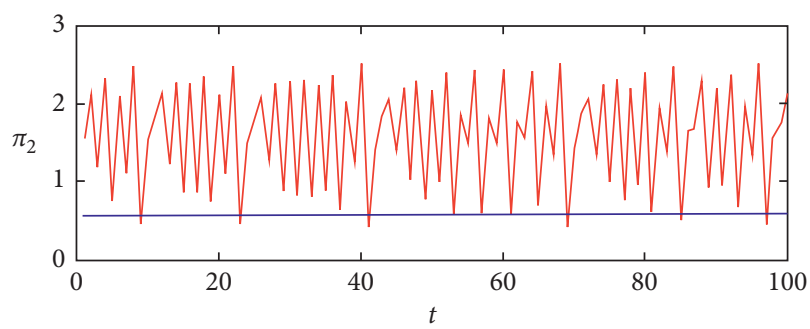

(b)

Figure 16: Effects of control factor $k$ on $\pi_{1}, \pi_{2}(k=0.4)$.

policymaker cost and the value of rent into Tullock's lottery model of rent-seeking. Their contribution is that the political environment could enhance competition and help rentseekers make decisions.

In this paper, players adjust strategy behaviors in a dynamic game process. We combine game theory with nonlinear dynamics to discuss the stability of Nash equilibrium. The results of this paper which is different from Godwin et al. [7] could be concluded: firstly, Theorem 1 has proved that the Nash equilibrium is unique and symmetrical in the rent-seeking game. In Theorem 2, locally asymptotic stability of Nash equilibrium is summarized. In addition, numerical simulation has investigated that the limit state of the system may be a complex state of period or chaos when the expenditure parameter is not in the stability region. The stability region of Nash equilibrium will enlarge as the competition intensity or policymaker cost increases. As the competition parameter increases, chaos would be weakened in a rent-seeking market. Ultimately, we present strange attractors and the sensitivity on initial values in a chaotic rent-seeking market. Chaos is controlled by the delay feedback control method.

\section{Data Availability}

No data were used to support this study. Numerical simulation was used to illustrate the theory results.

\section{Conflicts of Interest}

The authors declare that they have no conflicts of interest.

\section{Acknowledgments}

This study was funded by China Postdoctoral Science Fund (Grant no. 2019M652051), China Education Ministry Fund (Grant no. 19YJC630087), and Hangzhou Philosophy and Social Sciences Fund (Grant no. Z20JC098).

\section{References}

[1] G. Tullock, "The welfare costs of tariffs, monopolies, and theft," Economic Inquiry, vol. 5, no. 3, pp. 224-232, 1967.

[2] A. O. Krueger, "The political economy of the rent-seeking society," American Economic Review, vol. 64, pp. 291-303, 1974.

[3] J. M. Buchanan, R. D. Tollison, and G. Tullock, Toward a Theory of the Rent-Seeking Society, A \& M University Press, College Station, TX, USA, 1980.

[4] W. R. Dougan and J. M. Snyder, "Are rents fully dissipated?" Public Choice, vol. 77, no. 4, pp. 793-813, 1993.

[5] R. A. Posner, "The social costs of monopoly and regulation," Journal of Political Economy, vol. 83, no. 4, pp. 807-827, 1975.

[6] G.-Z. Sun and Y.-K. Ng, "The effect of number and size of interest groups on social rent dissipation," Public Choice, vol. 101, no. 3/4, pp. 251-265, 1999.

[7] R. K. Godwin, E. J. López, and B. J. Seldon, "Incorporating policymaker costs and political competition into rent-seeking games," Southern Economic Journal, vol. 73, no. 1, pp. 37-54, 2006.

[8] R. M. S. Costa, T. Van Andel, P. Pavone, and S. Pulvirenti, "The pre-Linnaean herbarium of Paolo Boccone (1633-1704) kept in Leiden (Netherlands) and its connections with the imprinted one in Paris," Plant Biosystems-An International Journal Dealing with All Aspects of Plant Biology, vol. 152, no. 3, pp. 489-500, 2018. 
[9] G. Ferrauto, R. M. S. Costa, P. Pavone, and G. L. Cantarella, "Human impact assessment on the Sicilian agroecosystems through the evaluation of melliferous areas," Annali di Botanica, vol. 3, pp. 237-244, 2013.

[10] Y. Peng and L. Ning, "Study on quality decisions in supply chain considering the lagged time and retailers competition," Discrete Dynamics in Nature and Society, vol. 2020, Article ID 7482967, 13 pages, 2020.

[11] X. Zhang, X. Yuan, and D. Zhang, "Research on closed-loop supply chain with competing retailers under government reward-penalty mechanism and asymmetric information," Discrete Dynamics in Nature and Society, vol. 2020, Article ID 7587453, 20 pages, 2020.

[12] H. N. Agiza, G. I. Bischi, and M. Kopel, "Multistability in a dynamic Cournot game with three oligopolists," Mathematics and Computers in Simulation, vol. 51, no. 1-2, pp. 63-90, 1999.

[13] S. Brianzoni, L. Gori, and E. Michetti, "Dynamics of a Bertrand duopoly with differentiated products and nonlinear costs: analysis, comparisons and new evidences," Chaos, Solitons \& Fractals, vol. 79, pp. 191-203, 2015.

[14] T. Dubiel-Teleszynski, "Nonlinear dynamics in a heterogeneous duopoly game with adjusting players and diseconomies of scale," Communications in Nonlinear Science and Numerical Simulation, vol. 16, no. 1, pp. 296-308, 2011.

[15] Q. G. Yi and X. J. Zeng, "Complex dynamics and chaos control of duopoly Bertrand model in Chinese air-conditioning market," Chaos, Solitons \& Fractals, vol. 76, pp. 231-237, 2015.

[16] E. Ahmed and M. F. Elettreby, "Controls of the complex dynamics of a multi-market Cournot model," Economic Modelling, vol. 37, pp. 251-254, 2014.

[17] T. Puu, "Chaos in duopoly pricing," Chaos Solitons \& Fractals, vol. 1, no. 6, pp. 573-581, 1991.

[18] G. I. Bischi, F. Lamantia, and D. Radi, "An evolutionary Cournot model with limited market knowledge," Journal of Economic Behavior \& Organization, vol. 116, pp. 219-238, 2015.

[19] J. Andaluz, A. A. Elsadany, and G. Jarne, "Nonlinear Cournot and Bertrand-type dynamic triopoly with differentiated products and heterogeneous expectations," Mathematics and Computers in Simulation, vol. 132, pp. 86-99, 2017.

[20] J. Ma and X. Pu, "The research on Cournot-Bertrand duopoly model with heterogeneous goods and its complex characteristics," Nonlinear Dynamics, vol. 72, no. 4, pp. 895-903, 2013.

[21] Y.-H. Zhang, W. Zhou, T. Chu, Y.-D. Chu, and J.-N. Yu, "Complex dynamics analysis for a two-stage Cournot duopoly game of semi-collusion in production," Nonlinear Dynamics, vol. 91, no. 2, pp. 819-835, 2018.

[22] Y. Peng and Q. Lu, "Complex dynamics analysis for a duopoly Stackelberg game model with bounded rationality," Applied Mathematics and Computation, vol. 271, pp. 259-268, 2015.

[23] Y. Peng, Q. Lu, and Y. Xiao, "A dynamic Stackelberg duopoly model with different strategies," Chaos, Solitons \& Fractals, vol. 85, pp. 128-134, 2016.

[24] L. Shi, Z. Sheng, and F. Xu, "Complexity analysis of remanufacturing duopoly game with different competition strategies and heterogeneous players," Nonlinear Dynamics, vol. 82, no. 3, pp. 1081-1092, 2015.

[25] A. Agliari, A. K. Naimzada, and N. Pecora, "Nonlinear dynamics of a Cournot duopoly game with differentiated products," Applied Mathematics and Computation, vol. 281, pp. 1-15, 2016.

[26] E. Ahmed, A. A. Elsadany, and T. Puu, "On Bertrand duopoly game with differentiated goods," Applied Mathematics and Computation, vol. 251, pp. 169-179, 2015.
[27] W. Yu and Y. Yu, "The complexion of dynamic duopoly game with horizontal differentiated products," Economic Modelling, vol. 41, pp. 289-297, 2014.

[28] Z. Ding, X. Zhu, and S. Jiang, "Dynamical Cournot game with bounded rationality and time delay for marginal profit," Mathematics and Computers in Simulation, vol. 100, pp. 1-12, 2014.

[29] A. A. Elsadany, "Dynamics of a delayed duopoly game with bounded rationality," Mathematical and Computer Modelling, vol. 52, no. 9-10, pp. 1479-1489, 2010.

[30] L. Gori, L. Guerrini, and M. Sodini, "A continuous time Cournot duopoly with delays," Chaos, Solitons \& Fractals, vol. 79, pp. 166-177, 2015.

[31] A. Matsumoto and F. Szidarovszky, "Delay dynamics of a Cournot game with heterogeneous duopolies," Applied Mathematics and Computation, vol. 269, pp. 699-713, 2015.

[32] J.-G. Du, Y.-Q. Fan, Z.-H. Sheng, and Y.-Z. Hou, "Dynamics analysis and chaos control of a duopoly game with heterogeneous players and output limiter," Economic Modelling, vol. 33, pp. 507-516, 2013.

[33] L. Xie and J. Ma, "Study the complexity and control of the recycling-supply chain of China's color TVs market based on the government subsidy," Communications in Nonlinear Science and Numerical Simulation, vol. 38, pp. 102-116, 2016.

[34] A. Dixit, "Comparative statics for oligopoly," International Economic Review, vol. 27, no. 1, pp. 107-122, 1986. 